\title{
(t)
}

\section{MOVIMENTOS SOCIAIS NA AMÉRICA LATINA: PRINCIPAIS ASPECTOS POSTOS AO DEBATE}

Social movements In Latin America: main aspects for debate

\section{Silene de Moraes Freire ${ }^{1}$ Maria Clara de Arruda Barbosa}

\section{RESUMO}

O artigo é fruto das pesquisas do Programa de Estudos de América Latina e Caribe (PROEALC) da UERJ e busca mapear os principais aspectos dos diversos movimentos sociais hoje em destaque na América Latina. As questões assinaladas são amplas e são temas para uma longa investigação que não se pretende esgotar nesse estudo. O objetivo é fornecer elementos capazes de contribuir para o debate imposto pelas agendas desses movimentos na

\footnotetext{
${ }^{1}$ Assistente Social, Mestre em Serviço Social pela UFRJ, Doutora em Sociologia pela USP, Professora Adjunta do Departamento de Política Social da FSS da UERJ, atual Coordenadora do Programa de Pós-Graduação Stricto Sensu da FSS da UERJ (Gestão 2010-2011). Coordenadora do Programa de Estudos de América Latina e Caribe (PROEALC-CCS/UERJ), Procientista da UERJ e pesquisadora do CNPq. E-mail: <silenefreire@gmail.com>, <silene-freire@ig.com.br>.

${ }^{2}$ Assistente Social, Mestranda do Programa de Pós-Graduação Stricto Sensu da FSS da UERJ. Bolsista de Mestrado da FAPERJ. Pesquisadora Associada do Programa de Estudos de América Latina e Caribe (PROEALC-CCS/UERJ). E-mail: <mariaclara.uerj@gmail.com>.
}

Temporalis, Brasilia (DF), ano 11, n.21, p.71-99, jan./jun. 2011. 


\section{tempordils}

BARBOSA, M. C. de A.; FREIRE, S. de M. MOVIMENTOS SOCIAIS

contemporaneidade construindo uma pauta de reflexão capaz de ultrapassar as interpretações pontuais e particularistas. Para desenvolver o mesmo, utilizamos como metodologia elementos fundamentais para a construção de uma investigação de caráter teórico-interpretativo. Desse modo, a metodologia incluiu as concepções teóricas de abordagem dos fatos selecionados para reflexão.

\section{PALAVRAS-CHAVE}

Movimentos Sociais. América Latina. Contemporaneidade.

\section{ABSTRACT}

This article is the result of research conducted as part of the State University of Rio de Janeiro (UERJ) Latin American and Caribbean Studies Program (PROEALC). It aims at mapping out the main aspects of the different social movements currently standing out in Latin America. The issues addressed are broad topics for a more extensive investigation, which this study does not intend to cover completely. The objective is to provide elements that are capable of contributing to the debate imposed by the agendas of these contemporary movements, building an agenda for reflection that can extend beyond particular and specific interpretations. In order to develop this agenda, the methodology used was based on elements that are fundamental to constructing a theoreticalinterpretative investigation. Thus, the methodology comprises theoretical concepts for approaching the facts chosen for reflection.

\section{KEYWORDS}

Social Movements. Latin America. Contemporaneity. 


\section{tempordils}

BARBOSA, M. C. de A.; FREIRE, S. de M. MOVIMENTOS SOCIAIS

\section{INTRODUÇÃO}

O presente artigo faz parte de nossas pesquisas acerca dos rumos dos movimentos sociais na América Latina contemporânea, realizadas no Programa de Estudos de América Latina e Caribe da Universidade do Estado do Rio de Janeiro. Para desenvolver o mesmo, utilizamos como metodologia elementos fundamentais para a construção de uma investigação de caráter teóricointerpretativo. Desse modo, a metodologia incluiu as concepções teóricas de abordagem dos fatos selecionados para reflexão. Também buscamos uma aproximação histórica com alguns momentos de protagonismos dos movimentos na América Latina. Aspectos de cada conjuntura, nacional e internacional foram levantados com o objetivo de inserir historicamente cada luta dos movimentos. Assim, a meta da narrativa do estudo apresenta sua consonância com a metodologia desenvolvida, dando sentido aos movimentos estudados e ressaltando sua importância em cada contexto. Entendemos por metodologia o caminho do pensamento e a prática exercida na abordagem da realidade.

Neste sentido, a metodologia ocupa um lugar central na teoria e está sempre referida a elas. Neste estudo também pretendemos oferecer um conjunto de análises capazes de contribuir para a compreensão do significado da experiência desses movimentos em nosso país. Diante disso, salientamos que a análise realizada conta com uma metodologia capaz de promover um embasamento teórico dos dados históricos empíricos para melhor fundamentarem os conceitos e reflexões. Não almejamos oferecer através de nossa investigação uma interpretação conclusiva dos rumos dos movimentos sociais na região. O objetivo é mostrar como a complexidade e a singularidade das experiências dos movimentos podem ser abordadas por meio de uma perspectiva genérica, que, articulada com determinações particulares, permite 


\section{tempordils}

BARBOSA, M. C. de A.; FREIRE, S. de M. MOVIMENTOS SOCIAIS

um delineamento totalizante, evidenciado nos seus vínculos com políticas mais amplas e suas semelhanças não circunstanciais com experiências desenvolvidas em outras sociedades. Assim sendo, ao considerarmos a particularidade e complexidade de nosso objeto de estudo, estamos enfatizando que o mesmo faz parte de uma totalidade, em movimento, repleta de contradições.

$\mathrm{Na}$ entrada do século XXI, pode-se perceber o reinado de regimes políticos democráticos que se instaurou em quase toda a América Latina até o final do decênio anterior, onde o neoliberalismo, como política econômica e como ideologia, tornou-se uma expressão aparente desses governos. O funcionamento da democracia política latino-americana durante os anos 1990 esteve cercado por baixos níveis de participação e mobilização da cidadania e ampliação da desigualdade econômico-social, acarretando num aprofundamento da crise da região e enfraquecimento da legitimidade política e ideológica desse potencial hegemônico, onde as políticas de ajuste fiscal deixaram de ser solução e passaram a desequilibrar economicamente o subcontinente. Podemos concluir que o surgimento de novas forças sociais e políticas, assim como o fortalecimento de forças construídas anteriormente, tornam $\mathrm{o}$ atual contexto um momento histórico particular em que os projetos tanto de continuidade como de ruptura com o neoliberalismo se evidenciam de forma mais concreta. É neste contexto que as análises dos movimentos sociais da América Latina ganham relevância, ajudando na compreensão do atual cenário, seus limites e possibilidades reais de mudanças nesse século que se inicia. Desse modo, o artigo buscou analisar em linhas gerais os principais aspectos dos movimentos sociais na América Latina com o objetivo de apontar os desafios postos ao debate. 


\title{
tempordilis
}

BARBOSA, M. C. de A.; FREIRE, S. de M. MOVIMENTOS SOCIAIS

\section{BREVES APORTES AO DEBATE}

Um dos primeiros desafios ao debate é perceber que a definição acerca do conceito de movimentos sociais não é unívoca, e vem se reconfigurando ao longo da história. Não são poucos os analistas que confundem a ideia de que constatar a existência de uma ação coletiva é o mesmo que atestar a presença de um movimento social. Obviamente, todo movimento social traz em si aspectos que representam ações coletivas, mas por outro lado, nem toda ação coletiva configura-se ou irá se configurar como movimento social ${ }^{3}$. Conforme observou GOHN (2008, p.7), "há diferentes paradigmas teóricos na atualidade para o estudo da ação dos sujeitos coletivos que produzem e reproduzem as demandas, ações, inovações ou até mesmo retrocesso nas ações coletivas organizadas" 4 . Contudo, não podemos deixar de registrar que movimentos sociais são sempre

\begin{abstract}
[...] ações coletivas de caráter sociopolítico, construídas por atores sociais pertencentes a diferentes classes e camadas sociais. Eles politizam suas demandas e criam um campo político de força social na sociedade civil. [...] As ações desenvolvem um processo social e político-cultural que cria uma identidade coletiva ao movimento, a partir de interesses em comum [...] (GOHN, 2000, p. 44).
\end{abstract}

É importante ressaltar nossa concordância com as análises de José Paulo Netto ao mencionar que há sem dúvida na atualidade uma

\footnotetext{
${ }^{3}$ A complexidade desse debate é aprofundada por Goss e Prudencio (2004, p. 75-91).

${ }^{4}$ Para Gohn (2008, p. 8), "[...] a produção teórica sobre os movimentos sociais no novo milênio defronta-se com novas demandas, novos conflitos e novas formas de organização, todos gerados pelas mudanças ocorridas nas últimas décadas do século XX, genericamente circunscritas como efeitos da globalização, em suas múltiplas faces".
} 


\section{tempordils}

BARBOSA, M. C. de A.; FREIRE, S. de M. MOVIMENTOS SOCIAIS

“[...] redução da vitalidade dos movimentos sociais das classes e camadas subalternas, que se expressa na perda de ponderação de movimentos sociais capazes de colocar em pauta algo mais que reivindicações pontuais e particularistas" (NETTO, 2004, p. 21). Tal afirmação não significa negar a existência e/ou importância dos movimentos sociais na atualidade, mas, ao contrário, buscar registrar a necessidade de compreensão das lutas sociais nessa nova etapa de subordinação massiva do trabalho ao capital. Como observou Fontes (2008, p. 33),

Estamos diante de um formidável impulso da acumulação capitalista, a cada dia mais destruidor, e sua destruição primeira incide sobre as formas de luta da própria classe trabalhadora, a qual precisa reconverter em mera força de trabalho. O capital precisa que ela seja disponibilizada, 'liberada', para que ele se perpetue. Por bem ou por mal (FONTES, 2008, p. 33).

A perda da centralidade da subjetividade de classe dos movimentos sociais não é recente. Durante a década de 1980 , pudemos assistir inclusive a novas tendências intelectuais que criticavam fortemente a pressuposição da existência de classes sociais, "[...] insistindo em que a vivência específica de cada segmento ou setor deveria ser enfatizada" (FONTES, 2008). Não por acaso, alguns autores começam a definir o conceito de movimentos sociais reconhecendo essas tendências interpretativas 5 . Para autores como Touraine (1998), por exemplo, as

5 Castells (1999; 2002; 2003) também concorda com as inflexões das experiências dos movimentos sociais ao afirmar que a sociedade contemporânea tem sido moldada pelos conflitos resultantes das contradições entre o processo de globalização e as identidades locais. Assim, em um contexto pautado pelas “[...] sociedades em rede [...]”, é imprescindível o fortalecimento das identidades locais. Nas palavras do autor, esse fortalecimento define-se como: "[...] o processo pelo qual um ator social se reconhece e constrói 


\section{tempordilis}

BARBOSA, M. C. de A.; FREIRE, S. de M. MOVIMENTOS SOCIAIS

classes sociais seriam algo de muito abstrato e não recobririam todas as modalidades da rica vida social das populações, como se o conceito de classe social fosse apenas uma modalidade classificatória ${ }^{6}$.

Levando em conta a existência de diferentes concepções sobre o tema, há que se perceber que os movimentos sociais, sejam tradicionais ou novos, clássicos ou contemporâneos, devem ser considerados em meio às transformações ocorridas no contexto econômico social, de um dado período histórico. No entanto, é notório que os movimentos sociais reivindicatórios "[...] são compostos por trabalhadores e precisam, mais do que nunca, estar atentos às formas de expansão contemporâneas do capital e de suas modalidades de subalternização, de passivamento e de redução do silêncio respeitoso através de um processo peculiar" (FONTES, 2008, p. 33), que pode ser definido, conforme Fontes (2008, p. 33) destacou como "[...] conversão mercantil-filantrópica de movimentos sociais de base popular”.

Assim, uma compreensão adequada dos movimentos sociais deve partir de uma análise totalizante das condições de reprodução do capital na atualidade, a partir das mudanças verificadas na sociedade, tanto na ordem econômica, como política, social e tecnológica.

\section{MOVIMENTOS SOCIAIS NA AMÉRICA LATINA CONTEMPORÂNEA}

É importante registrar que antes do século XX pouco ou quase nada da América Latina tinha importância no mundo. Somente no começo do século passado, alguns grandes acontecimentos

significado principalmente em determinado atributo cultural ou conjunto de atributos, a ponto de excluir uma referência mais ampla a outras estruturas sociais" (CASTELLS, 1999, p. 39).

${ }^{6}$ Sobre a importância do resgate do conceito de classes sociais na atualidade, ver Mattos (2007).

Temporalis, Brasilia (DF), ano 11, n.21, p.71-99, jan./jun. 2011. 


\section{tempordils}

BARBOSA, M. C. de A.; FREIRE, S. de M. MOVIMENTOS SOCIAIS

fizeram o mundo descobrir a região e ela a si mesma. Quase todos os caminhos dessa descoberta foram resultados de intensos conflitos sociais. O primeiro deles, conforme mencionou Sader (2003), foi o massacre da Escola Santa Maria de Iquique, no ano de 1907, no norte do Chile, onde milhares de trabalhadores mineiros em greve foram fuzilados diretamente do navio em que estavam os negociadores do governo chileno.

Pouco tempo depois, o México também demonstrava que a América Latina não poderia ser ignorada no plano internacional. Foi nesse país que explodiu a maior revolução social do subcontinente até então - a revolução mexicana, de Zapata e Pancho Villa, que deu a pauta dos movimentos populares durante meio século na América Latina: seu caráter nacionalista, agrário e anti-imperialista. Ainda na segunda década do século $\mathrm{XX}$, em Córdoba, na Argentina, surgiu a primeira reforma universitária um movimento que colocava o tema da democratização da educação e da incorporação do movimento estudantil às mobilizações sociais que viriam a se generalizar nas décadas seguintes, como observou Sader (2003, p.56).

As mudanças estruturais provocadas pela industrialização da região apontavam que o século $X X$ seria de revoluções e contrarrevoluções. Foi o século em que países do subcontinente protagonizaram um dos mais importantes movimentos históricos dentro do capitalismo - a industrialização de países da periferia, rompendo a dicotomia que identificava países ricos com 0 desenvolvimento industrial e esses com economias agrárias.

As ditaduras dos países do Cone Sul também marcaram a história da América Latina completando essa grande aventura no século XX que desembocou na virada liberal das duas últimas décadas do mesmo e desta entrada ao novo século. A América Latina foi o 


\section{tempordilis}

BARBOSA, M. C. de A.; FREIRE, S. de M. MOVIMENTOS SOCIAIS

laboratório privilegiado das experiências neoliberais no mundo. Nunca um modelo se generalizou tanto e fracassou tão estrepitosamente na história do subcontinente como o modelo neoliberal. Após mais de uma década de experiência neoliberal, as sociedades latino-americanas se encontram frente a desafios e dilemas extremamente graves que clamam por soluções urgentes. Um dos maiores desafios é a questão da pobreza que cresceu de forma avassaladora na região durante a década de 80 e nos anos 90 do século $X X^{7}$.

O significado do período aberto pela crise do neoliberalismo, especialmente na América Latina, como demonstrou Arcary (2008), exige um exame que problematize as principais tendências do capitalismo contemporâneo em perspectiva histórica. Como observou o autor,

$O$ 'dever de casa' liberal foi feito, sob a inspiração e monitoramento do FMI, pelos governos Menem e FHC, Fugimori e Gonzalo de Losada, entre tantos outros, a partir do início dos anos noventa, mas os investimentos estrangeiros, que foram prometidos em troca, preferiram como destino os países centrais,

7 Pesquisas recentes apontam para um paradigma persistente de subalternização da população latino-americana. Segundo o Relatório de Desenvolvimento Humano 2010, publicado para o Programa das Nações Unidas para o Desenvolvimento (PNUD), entre os 15 países mais desiguais do mundo, 10 se encontram na América Latina e Caribe. Na região, os países onde há menos desigualdade são Costa Rica, Argentina, Venezuela e Uruguai, com Gini (parâmetro internacionalmente usado para medir a concentração de renda desenvolvido pelo estatístico italiano Corrado Gini) inferior a 0,49. Na média, segundo o PNUD, o Índice de Gini da América Latina e do Caribe é 36\% maior que o dos países do leste asiático e $18 \%$ maior que os da África Subsaariana. Nota-se ainda o agravamento da desigualdade pelas discriminações atreladas ao gênero e raça, ou seja, mulheres negras e indígenas são, em geral, mais pobres. 


\section{tempordils}

BARBOSA, M. C. de A.; FREIRE, S. de M. MOVIMENTOS SOCIAIS

sobretudo os EUA, ou a Ásia, em especial a China. As sociedades latino-americanas permaneceram com economias de crescimento muito lento, ou estagnadas e, pior, dramaticamente desiguais, portando, politicamente muito instáveis (ARCARY, 2008, p. 43).

A realidade latino-americana e a situação contemporânea da região são extremamente complexas. Não podemos esconder o que de fato existe. O rigor da interpretação, os estudos capazes de guiarem conhecimentos sobre a América Latina representam hoje a maior possibilidade de construção de projetos emancipatórios eficazes para a região, livres de achismos otimistas e pessimistas que não ultrapassam o senso comum. Nesse sentido, ressaltamos, mais uma vez, a importância da análise dos movimentos sociais da região nesta direção.

Conforme observou Mészáros (2002, p. 251), “[...] o capital em si é absolutamente incapaz de se impor limites, não importando as consequências, nem mesmo a eliminação total da humanidade". Ou seja, se em sua fase de ascensão histórica, o capital ainda podia fazer algumas concessões, com o fim dessa fase, suas contradições não podem mais ser ocultadas. Sua própria expansão, agora, encontra barreiras importantes, diz Mészáros (2002, p. 946). Ou seja, "[...] a época de ouro do capitalismo [...]", configurada no segundo ciclo pós-guerra até os anos 70, precedeu um intenso período de recessão que se configura até hoje (HOBSBAWM, 1995, p. 253). A crise atual engendra ainda mais um reflexo do neoliberalismo, abarcado pelo amplo processo de privatizações, desregulamentação do mercado, flexibilizações e o intitulado estado mínimo; desse modo, é parte de um processo no qual as consequências para a América Latina são as piores possíveis. 


\section{tempordils}

BARBOSA, M. C. de A.; FREIRE, S. de M. MOVIMENTOS SOCIAIS

Outrossim, a tentativa de compreender a América Latina bem como o modo pelo qual a mesma se configura devem assentar-se na concreticidade que se situa em um dado tempo e espaço determinado historicamente ${ }^{8}$.

Ruy Mauro Marini, ao dissertar acerca do modelo de acumulação capitalista das sociedades dependentes latino-americanas, forneceu elementos para a compreensão dos fatores de produção que permitem a reprodução de capital nas economias centrais do capitalismo e, ao mesmo tempo, "[...] condiciona as burguesias da periferia, inferiorizadas na competição pelo mercado internacional, a induzir em nossas formações o processo de superexploração do trabalho" (MARINI apud SADER, 2009b, p. 31). Para Marini (apud SADER, 2009b), a emergência de uma nova ordem estatal na América Latina está relacionada a três fatores: a primeira tem a ver com as formas de participação da sociedade nas estruturas e exercício do poder, isto é, a democracia; uma segunda com a capacidade da sociedade para formular e implementar políticas atendendo a seus próprios interesses, no que diz respeito à autonomia e, portanto, à dependência; a terceira surge na perspectiva do futuro da América Latina no contexto das transformações pelas quais passa o mundo (SADER, 2009b).

As ideias de Marini (apud SADER, 2009b) ganham vigor quando pensamos no período inaugurado pela década de 1980 até o ano presente. Nesse espaço de tempo, a América Latina se caracterizou pela hegemonia do capital financeiro e do capital

\footnotetext{
${ }^{8}$ Nas palavras de Galeano (2005, p. 7): “Há dois lados da divisão internacional do trabalho: um em que alguns países se especializam em ganhar e outro em que se especializam em perder. Nossa comarca do mundo, que hoje chamamos de América Latina, foi precoce: especializou-se em perder desde os tempos em que os europeus do Renascimento se abalançaram pelo mar e fincaram os dentes em sua garganta. Passaram séculos e a América Latina aperfeiçoou suas funções".
}

Temporalis, Brasilia (DF), ano 11, n.21, p.71-99, jan./jun. 2011. 


\section{tempordils}

BARBOSA, M. C. de A.; FREIRE, S. de M. MOVIMENTOS SOCIAIS

internacional, resultante do neoliberalismo. Disso resultou uma derrota de vários segmentos que representavam as classes e camadas subalternas da região, o descenso do movimento de massas e a crise das organizações de esquerda. Quando tudo parecia consolidado, as crises cíclicas do processo de acumulação se manifestaram com maior força e em nível internacional. As reações populares passaram também a ter um efeito internacional maior. As perversidades sociais ficaram mais expostas. Assim sendo, podemos dizer que a partir do final do século XX entramos em um novo período da história latino-americana.

As características principais desse novo período são as manifestações de resistência popular que tiveram uma simbologia de rebeldia e de unidade continental muito grande, tais como: a revolta popular em Chiapas (1995); as mobilizações em Seatle (1999); as revoltas populares no Equador, Bolívia e Argentina, durante os anos de 2000 e 2001; e o início das reuniões do Fórum Social Mundial que, por sua vez, marcaram uma via de unidade das forças populares.

Todas essas experiências desencadearam um processo novo, em que algumas das forças políticas em presença passaram a priorizar a luta eleitoral como campo de disputa e derrota do neoliberalismo. As eleições ocorridas na região, a partir de 2002, revelaram candidatos antineoliberais (ainda que muitos deles no poder se manifestassem como neoliberais). Em realidade, não são poucas as necessidades de estudos que ajudem na compreensão dessa experiência tão recente e ainda em curso.

No ano de 2006, a América Latina mais uma vez foi palco de movimentos de resistência política ao contexto gerado pela aplicação das medidas neoliberais implementadas mais intensamente na região, a partir de fins dos anos 80 e durante a 


\section{tempordils}

BARBOSA, M. C. de A.; FREIRE, S. de M. MOVIMENTOS SOCIAIS

década de 1990. A contestação não partiu apenas dos movimentos sociais, mas de governantes eleitos com propostas de oposição a todo este receituário que vinha guiando as agendas nacionais latino-americanas. Neste cenário, a Venezuela - com o nacionalismo bolivariano resgatado pelo presidente Hugo Chávez e tendo ao seu lado Evo Morales, da Bolívia e Rafael Corrêa, do Equador - vem apresentando uma alternativa na direção de uma integração não subordinada dos países da região aos interesses do grande capital internacional. Do outro lado, o governo de Uribe, na Colômbia, e de Felipe Calderón, no México, exemplificam a perspectiva dependentista que historicamente marcou a região. Para além destas duas posições, há ainda outras tantas, que expressam a multiplicidade de possibilidades colocadas diante dos povos latino-americanos na atualidade. Este cenário abre um campo de reflexões necessárias e extremamente ricas.

Em suma, podemos dizer que a América Latina contemporânea tem fornecido o cenário para a emergência e multiplicação de movimentos sociais, os mesmos possuem características diferentes daqueles que vigeram em períodos anteriores e são poucos os que de fato conseguem obter maior impacto na sociedade inclusiva. Não são muitos os aspectos destes movimentos que podemos considerar inovadores. Mas é, sobretudo, a investigação desses aspectos que norteou nosso estudo, sem deixar de lado os elementos de continuidade que os movimentos sociais contemporâneos latino-americanos mantêm com aqueles que os antecederam.

Ao abordarmos os aspectos principais dos diversos movimentos sociais que têm hoje mais destaque na América Latina, é importante deixar claro que a pluralização dos movimentos sociais e a perda de uma clara hierarquia entre eles implicaram o que se poderia definir como $\mathrm{o}$ seu descentramento enquanto

Temporalis, Brasilia (DF), ano 11, n.21, p.71-99, jan./jun. 2011. 


\section{tempordils}

BARBOSA, M. C. de A.; FREIRE, S. de M. MOVIMENTOS SOCIAIS

subjetividades coletivas. Sua identidade é mais fluida quando se considera o somatório dos movimentos, o que evidencia um afastamento do caráter de classe dos mesmos.

Como é amplamente sabido, o sindicalismo - e, de modo mais geral, o movimento operário - foi visto por muitos anos como a grande expressão dos movimentos sociais nas primeiras fases da modernidade. Esta era a realidade, segundo Lins (2007), por exemplo, de países como o Brasil e muitos outros onde surgiram, nos anos 1980, novas experiências de ação sindical.

No final dos anos 1980, a crise nos países da Europa oriental impactou partidos e militantes sindicais em suas convicções ideológicas. Algumas lideranças tiveram, assim, dificuldades para continuar formulando estratégias contra o grande capital através das lutas sindicais. Mas os eventos mais devastadores para 0 proletariado só estavam começando. E os anos 90 deixam bem claro que este fenômeno prejudicou imensamente as finanças dos sindicatos, erodindo a base da organização e imprimindo ao movimento mudanças estratégicas ${ }^{9}$.

Ao estudar os movimentos sociais na América Latina, Domingues (2007) observou que o enorme espaço ocupado pelas relações de trabalho informais fez da organização dos trabalhadores algo mais complicado, que afetou diretamente a mobilização dos mesmos com a exceção parcial da Argentina, onde um modelo de acumulação quase intensivo e em parte baseado no consumo das massas gerou uma numerosa classe operária fabril e sindicalizada.

\footnotetext{
${ }^{9}$ Podemos dizer que as novas tecnologias, os novos métodos de organização do trabalho, o declínio da indústria e o crescimento dos serviços, o desemprego e o crescimento do setor informal são alguns dos fatores que levariam o sindicalismo à decadência no século XXI.
} 


\section{temporolis}

BARBOSA, M. C. de A.; FREIRE, S. de M. MOVIMENTOS SOCIAIS

Ainda segundo o mesmo autor, a crise da dívida nos anos 1980, o neoliberalismo na década seguinte, a reestruturação produtiva na mesma época, novas formas (mais liberais e desfavoráveis aos sindicatos) e, com efeito, o surgimento de fortes movimentos de desempregados apontavam rumos diferentes para os movimentos sociais da região. A Argentina, com o declínio do sindicalismo peronista e a organização dos desempregados como piqueteros, seria o exemplo mais eloquente desse processo, detalhadamente analisado por Domingues (2007).

Entretanto, ao chegarmos ao início da segunda década do século $X X I$, a verdade é que o sindicalismo segue sendo uma força a ser considerada, talvez mesmo o movimento social ainda mais importante, de maneira geral, na América Latina. Sua libertação do jugo corporativista no Brasil e na Argentina - com novos sindicatos e centrais de trabalhadores, permitindo pluralismo e mais capacidade de mobilização, por vezes, ainda que em condições econômico-sociais com frequência extremamente desfavoráveis garante-lhe uma posição de destaque nas lutas sociais ${ }^{10}$.

Cabe mencionar que já na década de 1990 surgiram movimentos sociais que não tinham muita expressão na década de 80 , como a própria questão dos idosos. Mas o principal deles, para Gohn (2003; 2007; 2008; 2010), foi o relativo à questão da violência e da criminalidade nas periferias, sem com isso ignorarmos as novas ações sobre o arcabouço institucional estatal que preside as interações, negociações, nos conselhos, fóruns etc.

\footnotetext{
10 Para uma compreensão aprofundada da questão sindical no contexto analisado, consultar: Alves (2000); Alves (1999); Antunes (2008); Boito jr (1999); Boito jr (1996); Giannotti (2002); Antunes; Silva (2004); Mattos (1998); Rodrigues (1999).
}

Temporalis, Brasilia (DF), ano 11, n.21, p.71-99, jan./jun. 2011. 


\section{tempordils}

BARBOSA, M. C. de A.; FREIRE, S. de M. MOVIMENTOS SOCIAIS

No início deste milênio, Gohn (2003, p.31-32) mapeou o panorama geral dos movimentos sociais em dez eixos temáticos das lutas e demandas no Brasil, que até hoje permanecem presentes, conforme os registros do Observatório Social da CLACSO ${ }^{11}$. São eles: lutas e conquistas por condições de habitalidade na cidade, nucleados pela questão de moradia; mobilizações e organização popular em torno de estruturas institucionais de participação na estrutura político-administrativa da cidade (Orçamento Participativo e Conselhos de Gestores); mobilizações e movimentos de recuperação de estruturas ambientais, físicoespaciais (como praças, parques), assim como de equipamentos e serviços coletivos (área da saúde, educação, lazer, esportes e outros serviços públicos degradados nos últimos anos pelas políticas neoliberais); mobilizações e movimentos contra o desemprego; movimentos de solidariedade e apoio a programas com meninos e meninas em situação de rua, adolescentes que usam drogas, portadores de HIV e de deficiências físicas; mobilização e movimentos dos sem-terra, na área rural e suas redes de articulações com as cidades via participação de desempregados e pessoas em situação de rua, nos acampamentos do MST (Movimento dos Trabalhadores Rurais Sem-Terra); movimentos envolvendo questões de gênero (mulheres e homossexuais) e movimentos étnico-raciais (índios e negros); movimentos rurais pela terra, reforma agrária e acesso ao crédito para assentamentos rurais; e movimentos contra as políticas neoliberais e os efeitos da globalização (contra a Alca, Fórum Social Mundial).

\footnotetext{
${ }^{11}$ Cabe registrar que desde a fundação, no ano 2000, do Observatório Social (OSAL) do Conselho Latino-Americano de Ciências Sociais (CLACSO), o Programa de Estudos de América Latina e Caribe (PROEALC) participa da pesquisa sobre os registros dos conflitos sociais no Brasil.
} 


\section{tempordilis}

BARBOSA, M. C. de A.; FREIRE, S. de M. MOVIMENTOS SOCIAIS

Ao analisar os novos aspectos dos movimentos sociais na América Latina, Domingues (2007) observou que mais surpreendente que qualquer outro fenômeno tem sido o que se poderia considerar uma "re-etnização" dos conflitos sociais. Segundo o autor, isso é verdade particularmente na região andina e na América Central (sobretudo na Guatemala e no México), mas ocorre por toda parte. Quéchuas, Aymaras, Mapuches, indígenas de Chiapas, Sonora e Yucatan parecem haver subitamente redescoberto serem "índios" - ou "povos originários", como preferem muitos.

Ainda segundo Domingues (2003; 2007), é importante observar que a complexificação das sociedades nacionais, sua crescente exposição à globalização e a valorização cada vez mais enfática de diferenças que o estado nacional nem queria nem mais podia simplesmente tentar homogeneizar ajudam a compreender os crescimentos desses movimentos étnicos na contemporaneidade. Torna-se assim possível entender como houve não apenas uma “[...] sistematização (racionalização), mas também uma politização das identidades étnicas, principalmente nos países com populações pré-colombianas mais numerosas", diz Domingues (2003, p.32).

Entretanto, Domingues (2003; 2007) também acha importante lembrar que não há razão para supor, esperar ou talvez sequer desejar que em todos esses países e regiões haja uma politização da etnicidade ${ }^{12}$.

\footnotetext{
${ }^{12}$ No Peru, por exemplo, não é este o caso. Aí é provável que a política e os movimentos sociais percorram outros caminhos, não menos legítimos, não menos populares que aqueles que emprestam destaque ao tema da identidade étnica.
} 


\section{tempordils}

BARBOSA, M. C. de A.; FREIRE, S. de M. MOVIMENTOS SOCIAIS

Cabe mencionar que a questão da raça vem permeando muitos movimentos sociais contra o racismo na contemporaneidade. Os mesmos repõem alguns dos temas já encontrados no que se refere à construção da identidade e muitos deles se articulam às lutas por ações afirmativas que visam reduzir as desigualdades que, durante a maior parte do século XX, foram encobertas nas sociedades que cultivaram a ideologia da mestiçagem e da democracia racial, como o caso brasileiro. Também é importante registrar o crescimento dos movimentos contra a homofobia em países como o Brasil e a Argentina, por exemplo.

Os movimentos sociais agrários também sofreram um forte recuo nos últimos anos; para muitos, a verdade é que não há mais fortes movimentos agrários ofensivos na América Latina - com a exceção do Brasil; ao mesmo tempo as lutas no campo seguem vigentes. Por outro lado, a agroindústria avançou extremamente no subcontinente, gerando um vasto proletariado rural e grande desemprego nessas regiões também. Com todos os problemas acirrados pelos ajustes neoliberais, o Brasil ainda abriga o maior movimento agrário das Américas, ao lado da guerrilha capitaneada pelas Forças Armadas Revolucionárias Colombianas (FARC).

Outros movimentos, importantes estão tendo hoje uma trajetória ondulante, como é o caso dos movimentos democráticos e por direitos humanos. Podemos dizer que os mesmos possuem, de fato, algum destaque na Argentina e no Chile - onde o peso das sanguinárias ditaduras dos anos 1970-1980 ainda se faz sentir, inclusive com o sequestro de testemunhas em processos contra assassinos e torturadores. O movimento ambientalista foi fortíssimo em vários países - especialmente no Brasil e no México -, mas declinou após a institucionalização formal do tema e a substituição do movimento enquanto tal por grupos profissionais, de pressão e por Organizações Não Governamentais (ONGs) 


\section{tempordilis}

BARBOSA, M. C. de A.; FREIRE, S. de M. MOVIMENTOS SOCIAIS

(Domingues, 2007). Uma nova onda em defesa do meio ambiente parece, porém, estar surgindo nesses países motivados pela crise ambiental mundial que desaba sobre o planeta e a humanidade. Por fim, o feminismo, poderoso nos anos 1980, se ongzou no final da década de 1990 e declinou em termos de criatividade e capacidade de mobilização cultural e política por todo subcontinente, conforme observou Domingues (2007). Um aspecto importante apontado por Fontes (2008, p. 33) - que interfere na ação destes movimentos e revela um fenômeno contraditório, surgido no próprio bojo das lutas sociais - “[...] consiste na admissão por parcelas do empresariado (e, em alguns casos, até mesmo no estímulo) de algumas demandas populares, direcionando-as através da elaboração de projetos financiáveis, para a produção de serviços de cunho assistencial" ${ }^{13}$.

Com relação aos movimentos religiosos, na América Latina, sabemos que no Brasil, no contexto dos anos 70 e 80 do século passado, as Comunidades Eclesiais de Bases (CEBs) possuíram um protagonismo de representação da sociedade civil capaz de lutar pela democratização do Estado brasileiro; entretanto, na ultima década do século XX, há uma inversão dessa crença. Nos anos 90, as CEBs entram numa vida submersa. Tal compreensão da trajetória desse movimento não pode deixar de perceber que as CEBs seguiram o caminho de grande parte dos movimentos sociais, que, em geral, entram em crise: de identidade, de rumos, de objetivos, definições, projetos, mobilizações etc. As causas são várias, destacando-se as de ordem interna, dadas pelas relações entre as bases, as lideranças e as assessorias num contexto neoliberal onde a fragmentação das experiências passa a guiar as

\footnotetext{
${ }^{13}$ Para Fontes (2008), “[...] essa conversão resulta num apassivamento das lutas sociais, encapsuladas em reivindicações de cunho imediato (corporativas) e circunscritas a níveis de consciência coletiva limitados".
} 


\section{tempordils}

BARBOSA, M. C. de A.; FREIRE, S. de M. MOVIMENTOS SOCIAIS

relações sociais. Contudo, os movimentos religiosos, não deixaram de alterar de todo os valores e modos de vida na América Latina. Não por acaso, em camadas médias ascendentes, em populações pobres da periferia e em comunidades indígenas urbanas ou rurais com forte participação, muitas vezes, nos processos políticos e na circulação de lideranças, é visível a influencia religiosa de algumas organizações. Esse é o caso, por exemplo, do katarismo e de seus desdobramentos contemporâneos na Bolívia re-etnicizada, que recebeu e forneceu quadros aos movimentos evangélicos, em particular na região de El Alto.

Nessa breve lista de movimentos sociais na América Latina na atualidade, registram-se, ainda, a retomada do movimento dos estudantes, especialmente no Chile, com a Revolta dos Pingüins (ZIBAS, 2008), e as ocupações em universidades no Brasil, especialmente as públicas, em luta pela melhoria da qualidade de ensino, contra reformas na educação e contra atos de corrupção e desvio de verbas públicas ${ }^{14}$. É importante mencionar que a área da educação, especialmente a educação na escola básica, tem sido fonte de protestos de grandes dimensões, a exemplo do México, em 2006, na região de Oaxaca ${ }^{15}$.

No Brasil, uma experiência mais particular do que as desenvolvidas nos demais países da América Latina vem se revelando como tendência que se consagraram nos governos Lula. Dada a centralidade das experiências brasileiras no contexto latinoamericano, achamos importante mencionar apenas como forma de registro o que vem sendo mencionado como essa tendência.

\footnotetext{
${ }^{14}$ A esse respeito, ver Freire (2008).

${ }^{15}$ Devemos destacar também que a área da educação - devido ao potencial dos processos educativos e pedagógicos para o desenvolvimento de formas de sociabilidade e constituição e ampliação de uma cultura política - passou a ser estratégica também para os movimentos populares, a exemplo do MST.
} 


\section{tempordilis}

BARBOSA, M. C. de A.; FREIRE, S. de M. MOVIMENTOS SOCIAIS

Quando da vitória petista sobre Alckmin, o sociólogo Oliveira (2007) alertou para os efeitos politicamente regressivos da hegemonia lulista: ao absorver transformisticamente ${ }^{16}$ as forças sociais antagônicas no aparato de Estado, desmobilizando as classes subalternas e os movimentos sociais, o governo Lula teria esvaziado todo o conteúdo crítico presente na longa "[...] era da invenção [...]" dos anos 1970-1980, tornando a política partidária praticamente irrelevante para a transformação social (OLIVEIRA, 2007, p. 9).

Para Oliveira, a medida da desmobilização praticada por Lula poderia ser apreendida pelo escasso interesse depositado pelos eleitores no pleito presidencial de 2006. O efeito social regressivo consistiria exatamente nisto: sob Lula, a política afastou-se dos embates hegemônicos travados pelas classes sociais antagônicas, refugiando-se na sonolenta e desinteressante rotina dos gabinetes.

A partir daí, Oliveira (2007) adiantou sua argumentação: no momento em que a "[...] direção intelectual e moral [...]" da sociedade brasileira parecia deslocar-se rumo às classes subalternas, tendo no comando do aparato de Estado a burocracia sindical oriunda do "[...] novo sindicalismo [...]", a ordem burguesa mostrava-se mais robusta do que nunca. A esse curioso fenômeno, em que parte "[...] dos de baixo [...]" dirige o Estado por intermédio do programa "[...] dos de cima [...]", Oliveira (2007) chamou "[...] hegemonia às avessas [...]": vitórias políticas, intelectuais e morais "[...] dos de baixo [...]" fortalecem " $[. .$. dialeticamente [...]" as relações sociais de exploração em benefício "[...] dos de cima [...]". Em suma, o governo Lula conseguiu coroar

\footnotetext{
${ }^{16}$ Transformismo foi o nome dado pelo pensador Antonio Gramsci (1891-1937) ao processo de absorção, pela classe dominante, de elementos ativos ou grupos inteiros, vindos tanto da base aliada como da adversária.
}

Temporalis, Brasilia (DF), ano 11, n.21, p.71-99, jan./jun. 2011. 


\section{tempordils}

BARBOSA, M. C. de A.; FREIRE, S. de M. MOVIMENTOS SOCIAIS

a incorporação de parte das reivindicações dos "[...] de baixo [...]" com a bem orquestrada reação ao subversivismo esporádico das massas representado pelo "[...] transformismo de grupos radicais inteiros [...]" ${ }^{17}$. Tal prática, segundo o autor, alterou significativamente as agendas dos movimentos sociais no Brasil, gerando um apassivamento funcional ao capital.

Sem dúvida, a dimensão dessas alterações ainda carece de investigação, mas já se constitui como mais um aspecto desafiador posto ao debate. Não podemos ignorar que também sobre os movimentos sociais incidem a coerção e o convencimento. Por isso, é importante registrar que as formas de apassivamento das lutas sociais também expressam restrições que circunscrevem os níveis de consciência coletiva ao plano elementar.

\section{CONSIDERAÇÕES FINAIS}

Todas as questões aqui assinaladas são amplas e são temas para uma longa investigação que não cabe nos limites de um artigo. Em síntese, é possível constatar uma grande pluralização dos movimentos sociais latino-americanos nos últimos anos, o que é fruto e ao mesmo tempo consiste em um dos elementos da crescente complexidade da modernidade em que se inserem.

\footnotetext{
${ }^{17}$ Da miríade de cargos no aparato de Estado, passando pelos muitos assentos nos conselhos gestores dos fundos de pensão, pelas altas posições em empresas estatais, pelo repasse de verbas federais para financiamento de projetos cooperativos, pela recomposição do aparato de Estado, pela reforma sindical que robusteceu os cofres das centrais sindicais etc., o lócus da hegemonia resultante de uma revolução passiva é exatamente o Estado. O fato é que os militantes sociais que passaram a investir esforços desmedidos na conservação das posições adquiridas no aparato transformaram 0 subversivismo inorgânico em consentimento ativo - para muitos, estatal.
} 


\section{tempordilis}

BARBOSA, M. C. de A.; FREIRE, S. de M. MOVIMENTOS SOCIAIS

Alguns deles, sem dúvida, pré-existiam a esse período mais recente, mas sua preeminência, situação de igualdade ou inclusive maior evidência, em relação ao movimento sindical e operário, ou camponês, é uma novidade que não se deve subestimar. Cabe ressaltar que em função de sua pluralidade, metas variáveis e novas alianças que não são necessariamente dadas desde sempre, começam a se configurar revelando os desafios desses movimentos na contemporaneidade. No Brasil, o período dos governos do ex-presidente Lula revelou ainda mais a complexidade da situação dos movimentos neste contexto.

Não obstante, é fundamental percebermos que a "[...] renovada presença da esquerda [...]” na América Latina, como destaca Boron (2004, p. 41), é resultado direto dos novos protagonismos presentes e atuantes em todo subcontinente. Protagonismos estes que do ponto de vista da forma e/ou do conteúdo inauguram uma retomada de ações de sujeitos coletivos na região. Estes, por sua vez, se conformaram como atores políticos centrais, sobretudo a partir da virada de século, ao longo das últimas décadas - pautadas politicamente pelos processos de redemocratização e economicamente por um avanço do conservadorismo ortodoxo financeiro em níveis de administração estatal que materializou a hegemonia do neoliberalismo na América Latina.

No que tange tal contexto, há que se destacar alguns aspectos desse processo. Entre eles, talvez o mais emblemático, que começa a ocorrer a partir da década de 1990, "[...] quando as entidades patronais, bancos de desenvolvimento e de cooperação internacional, grandes fundações privadas e o próprio Banco Mundial passariam a apoiar e a financiar resolutamente muitas entidades e a criar as suas próprias" (FONTES, 2008, p. 34), alterando o perfil de uma expressiva parcela da militância que começa a se converter em prestadora de serviços de apoio a

Temporalis, Brasilia (DF), ano 11, n.21, p.71-99, jan./jun. 2011. 


\section{tempordils}

BARBOSA, M. C. de A.; FREIRE, S. de M. MOVIMENTOS SOCIAIS

projetos sociais, profissionalizando-se como assessores de movimentos populares (FONTES, 2008). ${ }^{18}$

Tais aspectos acabam influenciando certa incapacidade instrumental do ponto de vista teórico da esquerda tradicional e clássica, por assim dizer, em reconhecer nestes discursos a real força de tensionamento com as estruturas de opressão e exploração presentes na América Latina.

Não há dúvidas de que as análises dos rumos dos movimentos sociais na atualidade revelam que estamos diante de fortes descentramentos das subjetividades de classe e de verdadeiros transformismos de grupos radicais inteiros. No entanto, é preciso entender que as transformações sofridas pelos movimentos sociais no Brasil e nos demais países latino-americanos, com a efetivação da agenda política neoliberal, não ocorreram por "[...] geração espontânea [...]", nem por demanda de sua clientela, mas, sim, abarcadas por diversas orientações encontradas nos principais documentos dos organismos multilaterais, como o Banco Mundial, assim como na cartilha do Consenso de Washington. Não por acaso é possível constatar em diferentes países da América Latina um progressivo movimento de institucionalização dos movimentos sociais que passaram a se estruturar como Organizações Não Governamentais (ONGs) - facilitando, dessa forma, o controle hegemônico do capital nos âmbitos social, político e econômico. Devido a dependência financeira das ONGs às suas agencias financiadoras, acaba sendo construída uma dependência política das mesmas. Esse é um exemplo simples de que a crise do capital

\footnotetext{
18 "Esse movimento ocorreu em paralelo a uma idealização do conceito de sociedade civil - como se este se limitasse apenas ao âmbito da vida popular" (FONTES, 2008, p. 32). A respeito das recentes armadilhas oriundas da notoriedade da sociedade civil, ver: FREIRE (2010).
} 


\section{tempordilis}

BARBOSA, M. C. de A.; FREIRE, S. de M. MOVIMENTOS SOCIAIS

expressa nas crises do Wellfare State e no modelo de produção fordista-taylorista-Keynesiano vai engendrar a necessidade não só de novos mecanismos de dominação "no campo, para a reprodução do capital, mas também de socialização de novos valores e novas regras de comportamento" (SIMIONATO, 1999, p. 82). Desse modo, não por acaso, a classe burguesa busca "[...] eliminar os antagonismos entre projetos de classe distintos, no intuito de construir um consenso ativo em nome de uma falsa visão universal da realidade social. Procede-se, assim, a uma verdadeira reforma intelectual e moral, sob a direção da burguesia" (SIMIONATO, 1999, p. 82, grifos da autora).

Em suma, estamos diante de novas experiências dos movimentos sociais cujos desafios postos para compreensão exigem um esforço de pesquisa, reflexão e ação que não podemos nos furtar. Acreditamos que o principal desafio posto ao debate é resgatar a centralidade da luta de classes como única possibilidade de fazer avançar de fato as lutas dos movimentos sociais.

\section{REFERÊNCIAS}

ALVES, G. Mundialização do capital e acumulação flexível: a nova degradação do trabalho na era da globalização. Londrina: Práxis, 1999.

O novo (e precário) mundo do trabalho: reestruturação produtiva e crise do sindicalismo. São Paulo: Boitempo, 2000.

ANTUNES, L. R. Reestruturação produtiva e sistema bancário: movimento sindical bancário brasileiro nos anos 90. Tese (Doutorado em Economia Aplicada) - Instituto de Economia, Unicamp, 2008. 


\section{tempordils}

BARBOSA, M. C. de A.; FREIRE, S. de M. MOVIMENTOS SOCIAIS

ANTUNES, R.; SILVA, M. A. M. (Org.). O avesso do trabalho. São Paulo: Expressão Popular, 2004.

ARCARY, V. Não há alternativa? O “day after” do neoliberalismo segundo István Mészáros. Revista Em Pauta, Rio de Janeiro, n. 21, p.37-50, jul. 2008. Disponível em: <http://www.epublicacoes.uerj.br/index.php/revistaempauta/article/viewFile/88/8 $1>$.

BOITO JR, A. Hegemonia neoliberal e sindicalismo no Brasil, Crítica Marxista, São Paulo, v. 1, n. $3,1996$.

. Política neoliberal e sindicalismo no Brasil. São Paulo: Xamã, 1999.

BORON, A. La izquierda latinoamericana a comienzos del siglo XXI: nuevas realidades y urgentes desafíos. Revista OSAL, Buenos Aires, n. 13, p. 41-56, 2004.

CASTELLS, M. Sociedade em rede. Rio de Janeiro: Paz e Terra, 1999.

. O poder da identidade. 3. ed. São Paulo: Paz e Terra, 2002.

. Fim de milênio. 3. ed. São Paulo: Paz e Terra, 2003.

DOMINGUES, J. M. Vida cotidiana, história e movimentos sociais. In: _. Ensaios de sociologia. Belo Horizonte: Editora UFMG, 2003. p. 29-52.

. Os movimentos sociais latino-americanos: características e potencialidades. Análise de Conjuntura OPSA, Rio de Janeiro, n. 2., p.20-37, fev. 2007. Disponível em: 


\section{tempordilis}

BARBOSA, M. C. de A.; FREIRE, S. de M. MOVIMENTOS SOCIAIS

<http://bibliotecavirtual.clacso.org.ar/ar/libros/brasil/iuperj/doming ues.pdf.>. Acesso em: 27 jun. 2011.

FONTES, V. Capitalismo, imperialismo, movimentos sociais e lutas de classes. Revista Em Pauta, Rio de Janeiro, n. 21, jul. 2008, p. 2636.

FREIRE, S. de M. . Movimento estudantil no Brasil: lutas passadas, desafios presentes. Revista RHELA, Bogotá, v. 11, p.131-146, 2008. Disponível em :

$<$ http://www.rhela.rudecolombia.edu.co/index.php/rhela/article/vie wFile/145/143>.

. As armadilhas da recente notoriedade da sociedade civil no Brasil. In: FREIRE, S. de M., FREIRE, L. M. B. e CASTRO, A. T. B. Serviço social, política social e trabalho. 3. ed. São Paulo: Cortez, 2010.

GALEANO, E. As veias abertas da América Latina. 45. ed. Rio de Janeiro: Paz e Terra, 2005.

GIANNOTTI, V. Força Sindical: a central neoliberal de Medeiros a Paulinho. Rio de Janeiro: Mauad, 2002.

GOHN, M. da G. Teoria dos movimentos sociais: paradigmas clássicos e contemporâneos. 2. ed. São Paulo: Loyola, 2000.

. Movimentos sociais no Início do Século XXI. Petrópolis:

Vozes, 2003.

. (Org.) Movimentos sociais no século XXI. 3. ed. Petrópolis:

Vozes, 2007. 


\section{temporalis}

BARBOSA, M. C. de A.; FREIRE, S. de M. MOVIMENTOS SOCIAIS

. Abordagens teóricas no estudo dos movimentos sociais na

América latina. Cad. CRH, Salvador, v. 21, n. 54, set./dez. 2008.

Disponível em: <http://www.scielo.br>. Acesso em: 28 jun. 2011.

. Movimentos sociais e redes de mobilizações civis no Brasil

contemporâneo.

Petrópolis: Vozes, 2010.

GOSS, K. P.; PRUDENCIO, K. O conceito de movimentos sociais revisitado. Revista Eletrônica dos Pós-Graduandos em Sociologia Política da UFSC, v. 1, n.2, jan. /jul. 2004, p. 75-91. Disponível em: <http://www.periodicos.ufsc.br/index.php/emtese/issue/view/1353.

HOBSBAWM, E. A era dos extremos: o breve século XX (1914-1991). São Paulo: Cia das Letras, 1995.

\section{LINS, J. P. Desafios da formação de sindicalistas na}

contemporaneidade. 2007. Dissertação (mestrado) - Universidade do Estado do Rio de Janeiro.

MATTOS, M. B. Classes Sociais e Lutas de Classes: a atualidade de um debate conceitual. Em Pauta, Rio de Janeiro, n. 20, p. 33-56, 2007. Disponível em: <http://www.epublicacoes.uerj.br/index.php/revistaempauta/article/viewFile/158/1 $83>$.

. Novos e velhos sindicalismos no Rio de Janeiro (1955-1988). Rio de Janeiro: Vício de Leitura, 1998.

MÉSZÁROS, I. Para além do capital. Trad. de Paulo Cezar Castanheira e Sérgio Lessa. Campinas: Boitempo, 2002. 


\section{tempordilis}

BARBOSA, M. C. de A.; FREIRE, S. de M. MOVIMENTOS SOCIAIS

OLIVEIRA, F. de. Hegemonia às Avessas. Revista Piauí, Rio de Janeiro, p.9-12, jan. 2007.

NETTO, J. P. A conjuntura brasileira: o Serviço Social posto à prova. Revista Serviço Social e Sociedade, São Paulo, ano 25, n.79, p. 5-43, set. 2004.

RODRIGUES, L. M. Destino do sindicalismo. São Paulo: Edusp, 1999.

SADER, E. A vingança da história. São Paulo: Boitempo, 2003.

- A nova toupeira: os caminhos da esquerda latino-americana.

São Paulo: Boitempo, 2009 a.

. Ruy Mauro, intelectual revolucionário. In: SADER, E.; SANTOS, T. dos (Coord). A América Latina e os desafios da globalização: ensaios dedicados a Ruy Mauro Marini. Rio de Janeiro: PUC-Rio; São Paulo: Boitempo, 2009 b.

SIMIONATO, I. As expressões ideoculturais da crise capitalista da atualidade. In: CFESS; ABEPSS. Capacitação em Serviço Social e política social: Módulo 1: Crise Contemporânea, Questão Social e Serviço Social. Brasília: CEAD, 1999.

TOURAINE, A. Crítica da modernidade. 5. ed. Petrópolis: Vozes, 1998.

ZIBAS, D. A Revolta dos Pingüins e o novo pacto educacional chileno. Revista brasileira de educação, São Paulo, v.13, n.38, p. 199-220, 2008. 
